Atmos. Meas. Tech., 5, 999-1013, 2012

www.atmos-meas-tech.net/5/999/2012/

doi:10.5194/amt-5-999-2012

(c) Author(s) 2012. CC Attribution 3.0 License.

\title{
Continuous measurements of methane mixing ratios from ice cores
}

\author{
C. Stowasser ${ }^{1}$, C. Buizert ${ }^{1}$, V. Gkinis ${ }^{1}$, J. Chappellaz ${ }^{3}$, S. Schüpbach ${ }^{2}$, M. Bigler ${ }^{2}$, X. Fä̈n ${ }^{3}$, P. Sperlich ${ }^{1}$, \\ M. Baumgartner ${ }^{2}$, A. Schilt ${ }^{2}$, and T. Blunier ${ }^{1}$ \\ ${ }^{1}$ Centre for Ice and Climate, Niels Bohr Institute, University of Copenhagen, Juliane Maries Vej 30, \\ 2100 Copenhagen, Denmark \\ ${ }^{2}$ Physics Institute, Climate and Environmental Physics and Oeschger Centre for Climate Change Research, \\ University of Bern, Sidlerstrasse 5, 3012 Bern, Switzerland \\ ${ }^{3}$ Laboratoire de Glaciologie et Geophysique de l'Environnement, CNRS and University of Grenoble, 54 rue Moliere - \\ Domaine Universitaire, 38400 St Martin d'Heres, France
}

Correspondence to: C. Stowasser (stowasser@nbi.ku.dk)

Received: 6 December 2011 - Published in Atmos. Meas. Tech. Discuss.: 9 January 2012

Revised: 25 April 2012 - Accepted: 26 April 2012 - Published: 9 May 2012

\begin{abstract}
This work presents a new, field-deployable technique for continuous, high-resolution measurements of methane mixing ratios from ice cores. The technique is based on a continuous flow analysis system, where ice core samples cut along the long axis of an ice core are melted continuously. The past atmospheric air contained in the ice is separated from the melt water stream via a system for continuous gas extraction. The extracted gas is dehumidified and then analyzed by a Wavelength Scanned-Cavity Ring Down Spectrometer for methane mixing ratios. We assess the performance of the new measurement technique in terms of precision ( $\pm 0.8 \mathrm{ppbv}, 1 \sigma)$, accuracy ( $\pm 8 \mathrm{ppbv})$, temporal (ca. $100 \mathrm{~s}$ ), and spatial resolution (ca. $5 \mathrm{~cm}$ ). Using a firn air transport model, we compare the resolution of the measurement technique to the resolution of the atmospheric methane signal as preserved in ice cores in Greenland. We conclude that our measurement technique can resolve all climatically relevant variations as preserved in the ice down to an ice depth of at least $1980 \mathrm{~m}$ (66000 yr before present) in the North Greenland Eemian Ice Drilling ice core. Furthermore, we describe the modifications, which are necessary to make a commercially available spectrometer suitable for continuous methane mixing ratio measurements from ice cores.
\end{abstract}

\section{Introduction}

Atmospheric methane $\left(\mathrm{CH}_{4}\right)$ is the second most important anthropogenic greenhouse gas, and a sensitive indicator of climate change and millennial-scale temperature variability. Records obtained from ice cores show $\mathrm{CH}_{4}$ variability of ca. 300 to 800 parts per billion by volume (ppbv) over the last $800 \mathrm{kyr}$ both on the orbital time scale of glacialinterglacial cycles (Loulergue et al., 2008), and on the millennial time scale of abrupt Dansgaard-Oeschger cycles (Chappellaz et al., 1993). Due to its short atmospheric lifetime, atmospheric $\mathrm{CH}_{4}$ variations can be very abrupt, allowing synchronization of ice core chronologies from both hemispheres (e.g. Blunier and Brook, 2001; Blunier et al., 2007; Capron et al., 2010). To capture atmospheric variability on the centennial to decadal scale, and to maximize the precision of interhemispheric synchronization, high resolution $\mathrm{CH}_{4}$ ice core records are desirable (Schüpbach et al., 2011). $\mathrm{CH}_{4}$ mixing ratio measurements need to be of high precision and accuracy to resolve small details in the records, such as the interhemispheric gradient (IHG) that reflects the latitudinal source distribution. The IHG, obtained by comparing Greenlandic and Antarctic records, is as small as $15 \mathrm{ppb}$ during glacial conditions (Dällenbach et al., 2000), requiring a combined precision and accuracy of \pm 5 ppbv. 
Measurements of $\mathrm{CH}_{4}$ mixing ratios from ice cores are typically based on gas chromatography (e.g. Sowers et al., 1997; Flückiger et al., 2004; Mitchell et al., 2011). Here, the air is extracted from individual ice core samples either by a dry (crushing or grating) or wet (melt-refreeze) extraction technique. In the column of the gas chromatograph, $\mathrm{CH}_{4}$ is separated from other gas species of the sample before mixing ratios can be determined e.g. via a thermal conductivity detector (for oxygen and nitrogen) and a flame ionization detector (for $\mathrm{CH}_{4}$ ). While measurements of $\mathrm{CH}_{4}$ mixing ratios from ice cores based on gas chromatography yield good reproducibility (4-15 ppbv), they are time consuming and labor-intensive, especially when aiming for high-resolution measurements over a large part of the ice core. Due to the separation of gas species within the column of the gas chromatograph, measurements are destructive and preclude consecutive measurements of several gas species from one ice core sample.

Güllük et al. (1997) developed a high-frequency modulated tunable diode laser absorption spectrometer for discrete measurements of $\mathrm{CH}_{4}$ and other gas mixing ratios from ice cores. The measurement technique is non-destructive, which allows for simultaneous measurements of up to four gas species from the same piece of ice. Uncertainty of $\mathrm{CH}_{4}$ mixing ratio measurements with this method varies between $\pm 13 \mathrm{ppbv}$ and $\pm 36 \mathrm{ppbv}$, depending on the age of the ice (Güllük et al., 1998). This technique is time consuming and labor intensive, since air is extracted from individual ice core samples similar to the techniques discussed above: Güllük et al. (1998) used a dry extraction technique, where the ice core sample is sublimated in a high-vacuum apparatus. Energy for sublimation is transferred to the ice sample by nearinfrared radiation. The temperature of the ice is kept below $-20^{\circ} \mathrm{C}$ to avoid the formation of liquid water and, thus, the dissolution of gas molecules in the liquid phase.

Recently, a semi-automated technique for measurements of $\mathrm{CH}_{4}$ mixing ratios from ice cores has been developed at the University of Bern (Schüpbach et al., 2009). This field-deployable technique utilizes a gas chromatograph for measurements of $\mathrm{CH}_{4}$ mixing ratios (reproducibility of 10 20 ppbv) in combination with a continuous melting device as used in Continuous Flow Analysis (CFA) systems (Kaufmann et al., 2008; Bigler et al., 2011). Due to the partly automated measurement technique and the continuous melting device, measurements are fast and achieve a high resolution of $15 \mathrm{~cm}$.

The new technique presented in this study is, to a high degree, automated, field-deployable and allows for nondestructive measurements of mixing ratios of multiple gas species from the same ice core sample (no separation or trapping of air components is required). A CFA system provides a continuous sample stream, i.e. a mixed flow of melted ice water and past atmospheric air. The air is separated from the melt water in two stages by means of a debubbler and a hydrophobic membrane, respectively. $\mathrm{CH}_{4}$ mixing ratios of the extracted air are measured with a Wavelength ScannedCavity Ring Down Spectrometer (WS-CRDS).

In order to make the commercially available WS-CRDS (Picarro Inc., CFADS36 $\mathrm{CO}_{2}\left|\mathrm{CH}_{4}\right| \mathrm{H}_{2} \mathrm{O}$ analyzer) suitable for continuous measurements of $\mathrm{CH}_{4}$ mixing ratios from ice cores in combination with a CFA system, we had to modify the spectrometer. The original version of the WS-CRDS is designed for higher gas flows compared to the gas flow available from CFA. We present the necessary modifications and characterize the performance of the modified WSCRDS in terms of stability, precision, accuracy and temporal resolution.

We characterize the combined field-deployed system of CFA, gas extraction and modified spectrometer in terms of stability, precision, accuracy and resolution, and present results of in-field measurements along ca. $27 \mathrm{~m}$ of the NEEM deep ice core (North Greenland Eemian Ice Drilling). Finally, we show that the resolution of our measurement technique is sufficient to resolve all climatically relevant variations in $\mathrm{CH}_{4}$ mixing ratio as preserved in the NEEM ice core down to a depth of at least $1980 \mathrm{~m}$ ( $66000 \mathrm{yr}$ before present).

\section{Methods}

\subsection{Experimental setup description}

Here we describe the experimental setup for continuous measurements of $\mathrm{CH}_{4}$ mixing ratios in combination with a CFA system as applied during the NEEM 2011 field season (Fig. 1). The CFA system was developed and operated by the University of Bern. On a heated melt head ice core rods (inner cross section of $2.6 \times 2.6 \mathrm{~cm}$, length $1.1 \mathrm{~m}$ ) are melted in a cold environment $\left(T \approx-20^{\circ} \mathrm{C}\right)$ at a rate of $3.2 \mathrm{~cm} \mathrm{~min}^{-1}$. This results in a stream of melt water and bubbles of past atmospheric air $\left(17 \mathrm{ml} \mathrm{min}^{-1}\right.$, ca. $10 \%$ air by volume).

In the warm laboratory of the CFA three peristaltic pumps and a debubbler (internal volume of ca. $0.8 \mathrm{ml}$ ) distribute the sample stream between several systems for chemical analysis (for details see Kaufmann et al., 2008; Schüpbach et al., 2009). In brief, the debubbler is a standard pipette tip sealed against ambient with a custom-made plug at the top including two holes for an inlet and outlet tube, respectively. The sample stream from the melt head enters through the inlet tube and air bubbles rise, driven by buoyancy, to leave the debubbler with some residual water through the outlet tube. Hence, no bubbles reach the tip of the pipette tip, where water is pumped away for analyses of chemical components and stable isotopes of water. An open split with small internal volume is installed downstream of the outlet tube and prevents pressure fluctuations in the debubbler that would affect the chemical analyses. From here the air and residual water $\left(3.2 \mathrm{ml} \mathrm{min}^{-1}\right.$, ca. $50 \%$ air by volume) are pumped through a heated transfer line (to avoid freezing of the sample) towards 


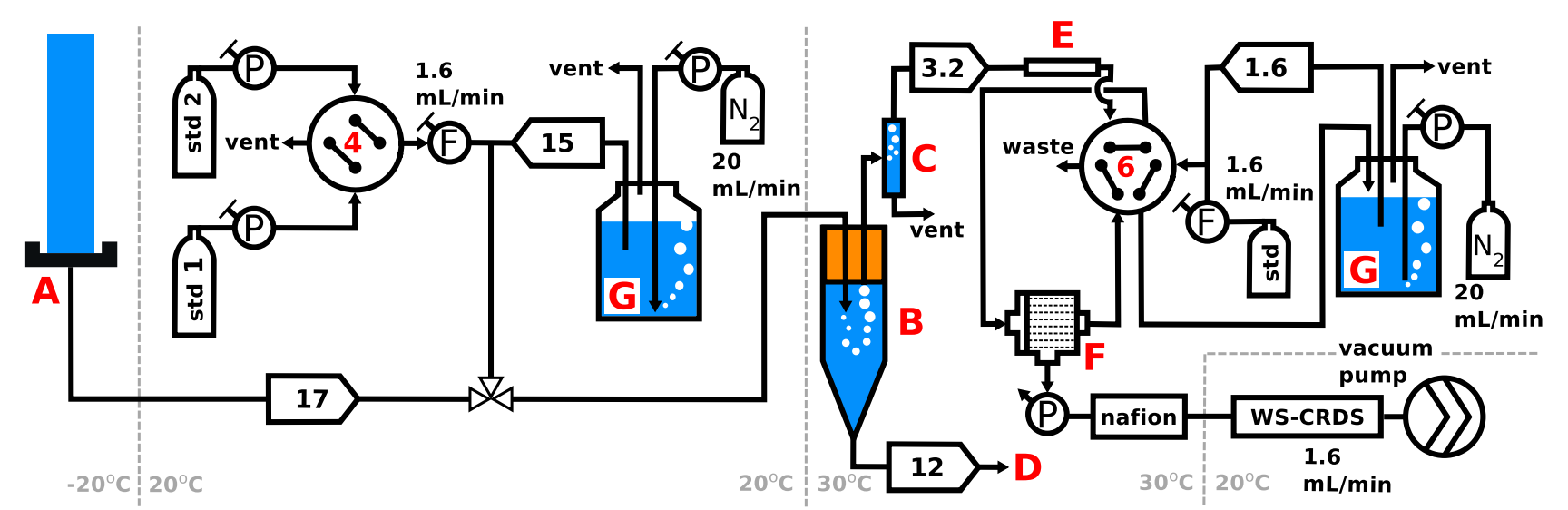

$x$ peristaltic pump with pump rate $x$ in $\mathrm{mL} / \mathrm{min}$

pressure / flow controller

(P) pressure transmitter

净 3-way valve

Fig. 1. Schematic drawing of the experimental setup for continuous measurement of $\mathrm{CH}_{4}$ mixing ratios as used during the NEEM 2011 field season. The ice core samples are melted on a heated melt head (A). By buoyancy, air bubbles are removed from the melt water in a sealed debubbler (B). An open split (C) prevents pressure changes in the debubbler. The air-free sample is distributed between different systems for analyses of the chemical composition of water and the ratio of stable isotopes of water (D). A heated tube (E) transfers gases and some residual water to a second warm laboratory for $\mathrm{CH}_{4}$ mixing ratio analysis. Here, a hydrophobic membrane module (F) separates the gas from any residual water. For calibration of the system deionized water is purged with nitrogen gas (G).

a second warm laboratory where $\mathrm{CH}_{4}$ mixing ratio analysis takes place.

The remaining melt water of the pressure decoupling unit overflow is removed with a module for continuous gas extraction (MicroModule $0.5^{\prime \prime} \times 1^{\prime \prime}$, G591, Membrana GmbH, Germany). With its internal volume of $5.4 \mathrm{ml}$, the MicroModule is small compared to other commercial systems for gas extraction and well-suited to degas small sample streams. Gas extraction is driven by the built-in vacuum pump of the WS-CRDS, which maintains a pressure gradient over a bundle of hydrophobic, gas-permeable membrane tubes within the module.

The performance of the gas extraction module depends on the pressure gradient over the hydrophobic membrane. Also, the mixing ratio of gas molecules dissolved in the melt water depends on both pressure and temperature of the sample stream. Thus, temperature and pressure should be constant on both the water and gas side of the gas extraction module to guarantee a stable gas extraction. For temperature stabilization the gas extraction module is located in a temperaturestabilized compartment $\left(T=30.0 \pm 0.2{ }^{\circ} \mathrm{C}\right)$. The pressure at the gas side of the gas extraction module is indirectly regulated to $700 \pm 20$ mbar by the internal electronic pressure regulator of the WS-CRDS, which primarily controls pressure in the sample cavity (EPC Proportional Control Valve, EPCA06SSVXAA, Parker Hannifin Corporation). This results in a pressure gradient of approximately $300 \mathrm{mbar}$ across the hydrophobic membrane of the module, which is sufficient to extract all visible air from the sample stream. Variations in the water-to-gas ratio in the sample stream as well as changes in the experimental setup (e.g. degradation of peristaltic pump tubing) introduce the observed pressure fluctuations of \pm 20 mbar at the gas side of the gas extraction module. In this experimental setup pressure is kept constant only on the gas side; an additional pressure regulator on the water side of the gas extraction module could improve the stability of the gas extraction.

The extracted air (ca. $1.6 \mathrm{ml} \mathrm{min}^{-1}$ ) is dried from water vapor while flowing through a two meter long custommade Nafion dryer (Nafion TT-020, Perma Pure LLC, $0.3 \mathrm{~mm}$ inner diameter) the outside of which is purged with ca. $20 \mathrm{ml} \mathrm{min}^{-1}$ of dry nitrogen gas (Nitrogen, technical grade, Air Liquide). The water mixing ratio of the dried sample is measured by the WS-CRDS to be ca. $0.003 \%$ by volume. By drying the sample, an otherwise necessary water vapor correction can be avoided (for more details about the water vapor correction see Rella, 2010). From here the dried sample gas is directed towards the WS-CRDS for $\mathrm{CH}_{4}$ mixing ratio analysis. The built-in diaphragm pump of the WSCRDS maintains a constant gas flow and creates a pressure drop over the hydrophobic membrane tubes of the gas extraction module. Note that all measurements are made on the ${ }^{12} \mathrm{CH}_{4}$ isotopologue, and therefore neglect variations of $\delta^{13} \mathrm{C}$ and $\delta \mathrm{D}\left(=\delta^{2} \mathrm{H}\right)$. However, given the natural isotopic abundances, combined with the small range of natural isotopic variation, the induced error is far below our detection limit.

The system idles as a new ice rod is placed on the melt head, enabling ambient air to enter the gas analysis system through the melt head. To prevent the ambient air from reaching the gas extraction module, a segmented flow of $3.2 \mathrm{ml} \mathrm{min}^{-1}$ (ca. $50 \%$ air by volume) of deionized water and bottled gas (mix of gases, Air Products, Belgium, $21 \% \mathrm{O}_{2}$, 

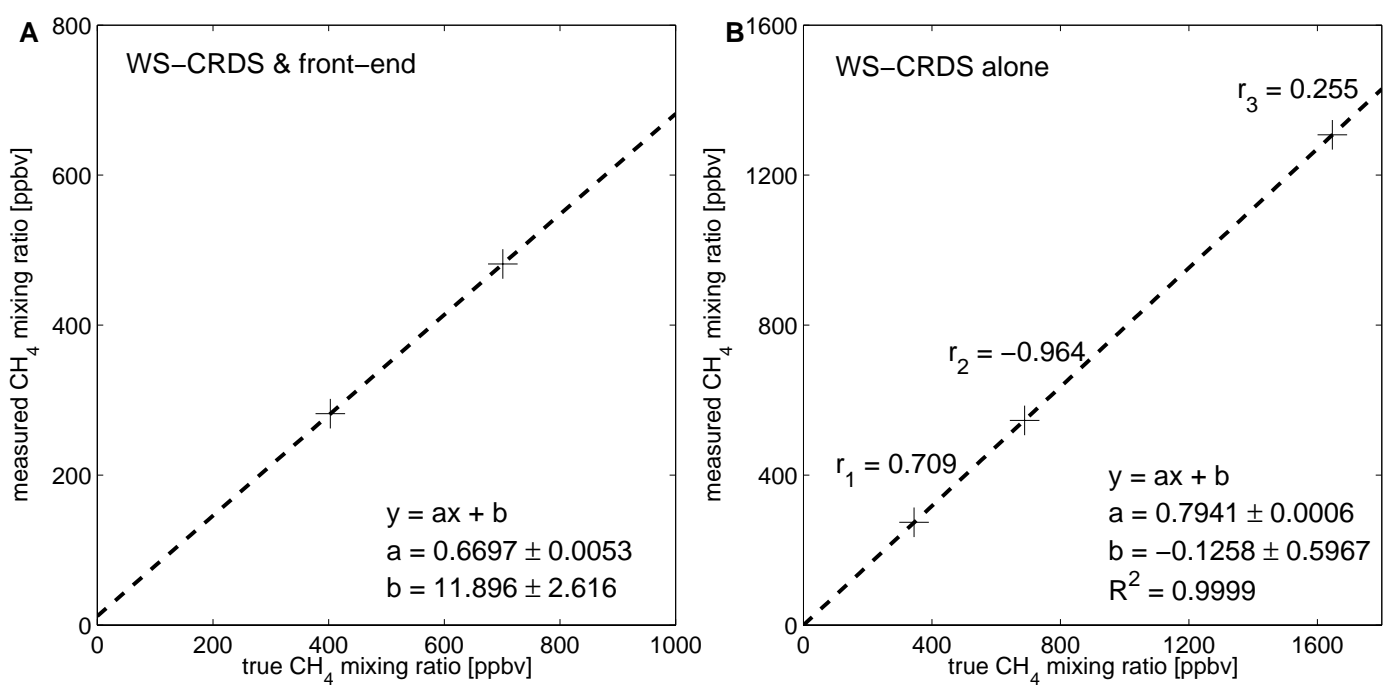

Fig. 2. (A) Calibration curve for the WS-CRDS plus front-end (except the melt head), where a mixture of gas and deionized water is injected downstream of the melt head. (B) Calibration curve of the WS-CRDS alone, where standard gas is directly injected into the spectrometer. $r_{1}$, $r_{2}$ and $r_{3}$ are the residuals of the fit given in ppbv.

$79 \% \mathrm{~N}_{2}, 701.2 \mathrm{ppbv}$ of $\mathrm{CH}_{4}$ ) is mixed in the temperaturestabilized compartment of the gas extraction system (top right in Fig. 1) and injected into the gas extraction module via the automated 6-port valve (\#6 in Fig. 1, Cheminert C22Z3186EH, VICI AG). Hereby the pressure in the gas extraction module and the gas flow through the WS-CRDS stay roughly constant between CFA runs (one CFA run is defined as measurements along $1.1 \mathrm{~m}$ of ice).

\subsection{Calibration}

For calibration a segmented flow of deionized water and bottled gas $\left(17 \mathrm{ml} \mathrm{min}^{-1}\right.$, ca. $10 \%$ air by volume $)$ is generated, and injected into the system downstream of the melt head (top left in Fig. 1). This segmented flow mimics the sample flow from the melt head and is treated just as an ice core sample from the moment it enters the system. The reservoir of the deionized water is purged with dry nitrogen gas at a rate of ca. $20 \mathrm{ml} \mathrm{min}^{-1}$ to keep the molar fraction of dissolved gas molecules roughly constant and to prevent contamination of the water with ambient air.

For day-to-day calibration of the system in the field, we made two gas mixtures $\left(21 \% \mathrm{O}_{2}, 79 \% \mathrm{~N}_{2}\right)$ with mixing ratios of $403.1 \mathrm{ppbv}$ and $701.2 \mathrm{ppbv}$, respectively. $\mathrm{CH}_{4}$ mixing ratios of both gas mixtures were determined prior to the field season using three synthetic air standard gases calibrated by NOAA (National Oceanic and Atmospheric Administration, Boulder $\mathrm{CO}, \mathrm{CH}_{4}$ mixing ratios of $344.3 \mathrm{ppbv}, 688.6 \mathrm{ppbv}$ and $1646.2 \mathrm{ppbv}$, respectively). Calibration takes place once a day using one of the two gas mixtures. Furthermore, a valve (\#4 in Fig. 1, C4WMPH, VICI AG) can be switched to abruptly change between the two gas mixtures. This enables us to determine the response of the experimental setup to a stepwise change in $\mathrm{CH}_{4}$ mixing ratio (see Sect. 3.2.1).

Figure 2a shows a typical calibration curve of the system for continuous measurements of $\mathrm{CH}_{4}$ mixing ratios (WSCRDS and front-end) as recorded during the field season. True $\mathrm{CH}_{4}$ mixing ratios of the two gas mixtures are plotted against the corresponding measurements of the WS-CRDS. Here, the front-end includes the complete system for gas extraction, except the melt head which we cannot account for during calibration since the segmented flow is injected downstream of the melt head (Fig. 1).

Each data point in Fig. 2a refers to continuous measurements of the corresponding gas mixture for ca. $30 \mathrm{~min}$. For linear regression we use Chi-square fitting, which is a special case of least-square fitting where every data point has its own, known standard deviation (for details see Press et al., 2007). Here the known standard deviations are the standard deviations of the continuous measurement series of the two gas mixtures. By using individual standard deviations for each measurement, we account for a dependance of the measurement precision on the $\mathrm{CH}_{4}$ mixing ratio of the sample gas. The optimal linear fit parameters $a$ and $b$ including their errors found from linear regression are shown in Fig. 2a. When using the calibration curve to find the correct values of measured $\mathrm{CH}_{4}$ mixing ratios the errors from the fit parameters propagate. Using propagation of error we determine the measurement accuracy to be \pm 8 ppbv for typical glacial/interstadial $\mathrm{CH}_{4}$ mixing ratios.

Prior to the field season we determined a calibration curve for the WS-CRDS without the front-end as shown in Fig. 2b. To this end, standard gas is injected directly into the spectrometer. $\mathrm{CH}_{4}$ mixing ratios of two NOAA-certified synthetic air standards $\left(\mathrm{CH}_{4}\right.$ mixing ratios of 344.3 and 
1646.2 ppbv, respectively) are plotted against the corresponding measurements of the WS-CRDS. Each data point refers to continuous measurements of the corresponding standard gas for ca. $30 \mathrm{~min}$. Again, we use propagation of error to determine the measurement accuracy of the WS-CRDS to be \pm 2 ppbv for typical glacial/interstadial $\mathrm{CH}_{4}$ mixing ratios. As a test we determine the $\mathrm{CH}_{4}$ mixing ratio of a third standard gas to be $686.8 \pm 2 \mathrm{ppbv}$ which is in agreement with the true mixing ratio of $688.8 \mathrm{ppbv}$.

We can conclude that the measurements of the WS-CRDS are more accurate when the spectrometer is measuring directly from a gas bottle ( $\pm 2 \mathrm{ppbv})$, compared to measurements in combination with our gas extraction system as described earlier ( $\pm 8 \mathrm{ppbv})$. This is due to instabilities in the gas extraction system and a better measurement precision of the WS-CRDS for direct measurements of bottled gas (see Sect. 2.3).

Figure 2a shows that the WS-CRDS in combination with the front end measures significantly less $\mathrm{CH}_{4}$ compared to the stand-alone instrument as shown in Fig. 2b. This is a result of the solubility of $\mathrm{CH}_{4}$ in water: prior to measurements of $\mathrm{CH}_{4}$ mixing ratio by the WS-CRDS in combination with the front-end, the calibration gas has been in contact with water from the moment it was mixed with deionized water until it reached the gas extraction module (Fig. 1). A significant amount of $\mathrm{CH}_{4}$ molecules are dissolved in the water and are not completely extracted by the gas extraction module. An estimation of the amount of dissolved $\mathrm{CH}_{4}$ molecules can be found in the interactive discussion (Stowasser et al., 2012).

The intersect of almost 12 ppbv in Fig. 2a suggests a leak in the front-end or, alternatively a non-linearity in the calibration curve. Neither a leak in the front-end, nor non-linearity of the calibration curve could be checked during field measurements due to the lack of a third calibration gas and a $\mathrm{CH}_{4}$-free gas, respectively.

\subsection{Stability and precision}

The stability of the system is characterized by investigating long-term drifts in the $\mathrm{CH}_{4}$ mixing ratio measurements. In the following we characterize the stability of different parts of the experimental setup and determine the precision of the corresponding $\mathrm{CH}_{4}$ mixing ratio measurements.

First we characterize the stability of the WS-CRDS in combination with the gas extraction module. For this, we introduce a segmented flow of deionized water and bottled gas $\left(3.2 \mathrm{ml} \mathrm{min}^{-1}\right.$, ca. $50 \%$ air by volume) into the setup via the 6-port valve (\#6 in Fig. 1). The green line in Fig. 3a shows $\mathrm{CH}_{4}$ mixing ratio measurements of this segmented flow over a period of ca. $1 \mathrm{~h}$. The measurement precision we state for the combination of WS-CRDS and gas extraction module is given by the standard deviation of the non-averaged time series shown in Fig. 3a which is 0.7 ppbv $(1 \sigma)$.

From this series of measurements we quantify the stability of the gas extraction system by applying an Allan variance test (described in detail by Werle, 2011). In brief, Allan variance (Allan, 1966) describes the variance of the mean of a series of measurements for different integration times. In the theoretical case of zero-drift measurements, increasing integration times would unboundedly decrease the variance and, thus, the standard deviation of the measurements. However, instrumental drifts will limit the decrease of the standard deviation for progressively longer integration times. The green line in Fig. 3b shows the Allan variance (or Allan plot) of the measurement series (green) in Fig. 3a. For integration times $\tau$ up to seven minutes the Allan variance decreases and averaging of the signal can decrease the standard deviation of the $\mathrm{CH}_{4}$ mixing ratio measurements. For longer integration times instrumental drifts overcome the benefits of signal averaging, and the Allan variance increases.

The same stability test has been conducted for the WSCRDS alone without the gas extraction module prior to the field season; we injected bottled gas into the WS-CRDS directly over a period of 3.5 days. For comparison we show a ca. $1 \mathrm{~h}$ long section from this stability test (red line in Fig. 3a). The precision for non-averaged measurements is ca. $0.6 \mathrm{ppbv}(1 \sigma)$. The Allan variance of the complete time series (red line in Fig. 3b) reveals that signal averaging with integration times up to ca. $30 \mathrm{~min}$ improves the variance. We conclude that the $\mathrm{CH}_{4}$ mixing ratio measurements of the WSCRDS are more stable when the WS-CRDS is measuring directly from a gas bottle compared to measurements in combination with the gas extraction module. Thus, the limiting factor in terms of the stability of our measurements are instabilities in the gas extraction module and not in the measurement of the WS-CRDS.

We could not test the stability of the complete experimental setup, i.e. the combination of WS-CRDS, gas extraction module and the CFA system. The calibration series described in Sect. 2.2 do include WS-CRDS, gas extraction module and CFA system (except the melt head) but are too short to perform an Allan variance test. The standard deviation of these calibration series is $0.8 \mathrm{ppbv}(1 \sigma)$. The calibration series do not include the melt head, but represent the closest estimate we can obtain for the precision of continuous measurements of $\mathrm{CH}_{4}$ mixing ratios from ice cores. Thus, we estimate the precision of our measurement technique to be ca. $0.8 \mathrm{ppbv}$.

The results from the Allan variance test of the WSCRDS alone show that the standard deviation of the averaged time series becomes larger than the standard deviation of the non-averaged time series $(0.6 \mathrm{ppbv})$ for integration time longer than $14 \mathrm{~h}$. This suggests that the WS-CRDS should be calibrated at least every $14 \mathrm{~h}$ to account for instrumental drifts and to optimize the performance of $\mathrm{CH}_{4}$ mixing ratio measurements.

The Allan variance tests of the WS-CRDS plus gas extraction module is too short to show integration times for which the standard deviation of the averaged time series becomes larger than the standard deviation of the non-averaged time 

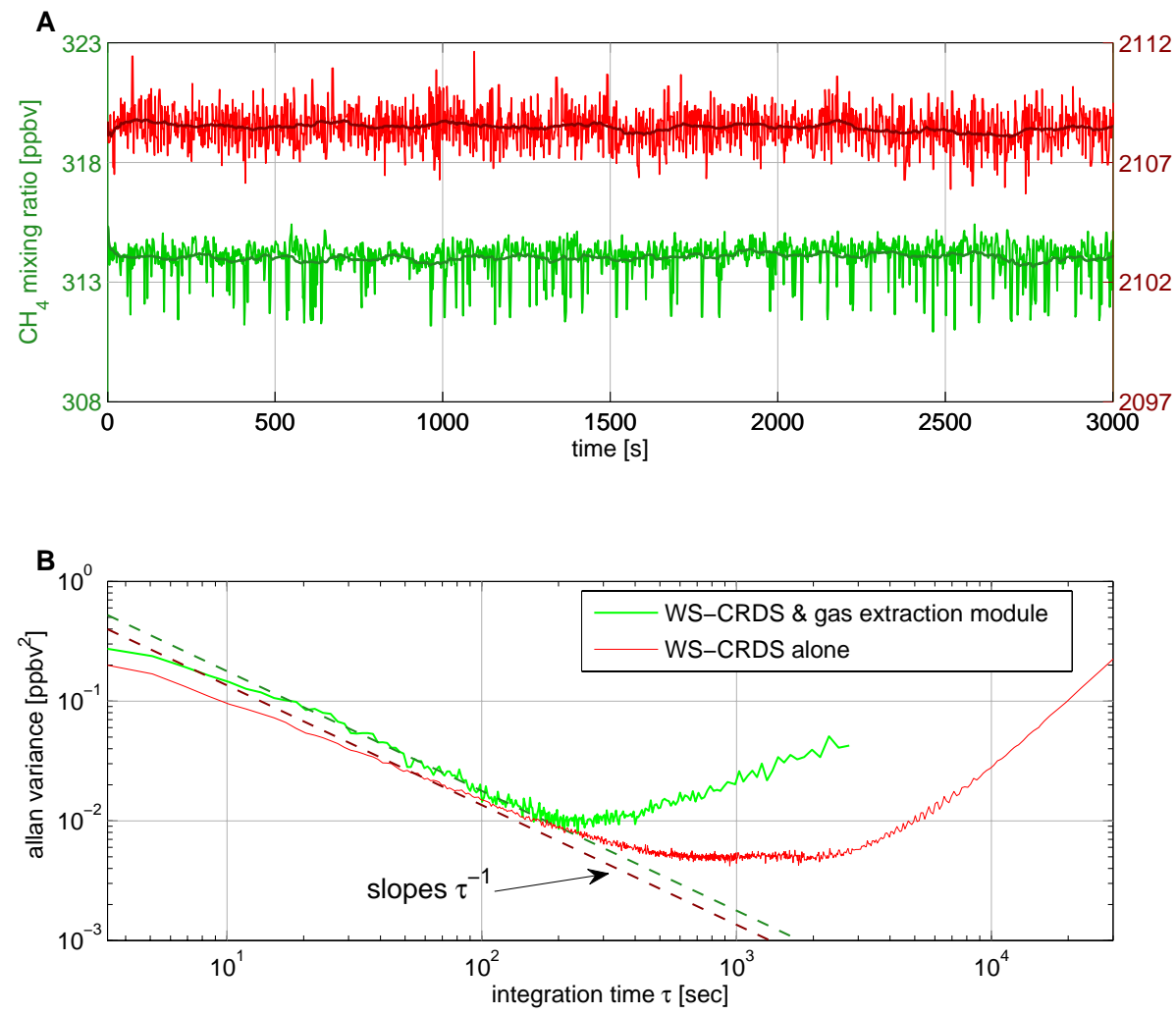

Fig. 3. (A) $\mathrm{CH}_{4}$ mixing ratios as measured by the WS-CRDS from bottled gas (red) and from a segmented flow of deionized water and calibration gas (green) over a period of approximately 50 minutes. The measurements from bottled gas were conducted over a period of 3.5 days (not shown here). Outliers in the $\mathrm{CH}_{4}$ mixing ratio measurement from deionized water and calibration gas are the result of a discrepancy between operating pressure and fitting routine (see Sect. 2.4.2). The average measurement frequency is $0.6 \mathrm{~Hz}$. To visualize short-term variations in the measurements we applied a one minute running average (dark red and dark green, respectively). (B) "Allan plot" of the two time series shown in the upper panel. Allan variance is plotted against the integration time $\tau$. In the case of random noise dominated measurements the "Allan plot" follows the $1 / \tau$ slope (dashed lines).

series. However, this will be the case for integration times shorter than $14 \mathrm{~h}$ as found for the WS-CRDS alone.

The results from the Allan variance tests suggest that more frequent calibrations could improve the performance of the system, since calibration of the system is done only once in $24 \mathrm{~h}$ (see Sect. 2.2). To find the optimal frequency of calibrations a longer Allan variance test needs to be conducted that includes the complete experimental setup.

It should be noted that the two "Allan plots" in Fig. 3b of the WS-CRDS plus gas extraction module (green line) and of the WS-CRDS alone (red line) reveal a typical low-pass filter characteristic: for integration times $\tau$ shorter than ca. $20 \mathrm{~s}$ and $37 \mathrm{~s}$, respectively, the Allan variances deviate from the slope of $1 / \tau$ (dashed lines), which represents the typical behavior in case of random noise (white noise) dominated measurements. This feature can be associated with software signal smoothing or a damping effect of fast concentration changes or fluctuations due to limitations in the gas sampling system (Werle, 2011). For our measurements of $\mathrm{CH}_{4}$ mixing ratios we exclude such an effect of the gas sampling system (front-end), because we observe a low-pass filtering effect also when the WS-CRDS is measuring bottled gas, where we assume a $\mathrm{CH}_{4}$ mixing ratio constant over time. This suggests that mainly the WS-CRDS and not the gas sampling system causes the observed low-pass filtering. Indeed, this effect is introduced by the software of the WS-CRDS, which applies an average (ca. $20 \mathrm{~s}$ ) over several mixing ratio measurements at the spectral baseline in order to increase the signal-to-noise ratio.

\subsection{Modifications on the WS-CRDS}

For $\mathrm{CH}_{4}$ mixing ratio analysis we use a modified version of a commercially available WS-CRDS from Picarro Inc. (CFADS36 $\mathrm{CO}_{2}\left|\mathrm{CH}_{4}\right| \mathrm{H}_{2} \mathrm{O}$ analyzer, for details see Crosson, 2008). In this section we present the modifications necessary to make the spectrometer applicable for continuous measurements from ice cores. 


\subsubsection{Gas flow and pump rate}

Gas flow through the WS-CRDS is maintained by a diaphragm pump which is located at the exhaust of the spectrometer. For precise spectroscopic measurements of mixing ratios a constant pressure in the optical cavity of the WSCRDS is crucial. A sensitive pressure transmitter records the cavity pressure and sends a feedback to a proportional control valve located at the outlet of the cavity. In this way the valve regulates the cavity pressure $(225.00 \pm 0.05 \mathrm{mbar})$ and the gas flow through the spectrometer.

By default, the WS-CRDS is designed for sample gas flows between $70-400 \mathrm{ml} \mathrm{min}^{-1}$. In the case of continuous measurements from ice cores the sample flow is set by the melt speed of the CFA system to $1.6 \mathrm{ml} \mathrm{min}^{-1}$. When operating the WS-CRDS at a such a low flow the cavity pressure is unstable and fluctuates around the set point. We applied the following modifications on the gas flow path to enable stable operation of the WS-CRDS at a gas flow of $1.6 \mathrm{ml} \mathrm{min}^{-1}$ :

- An orifice at the inlet of the WS-CRDS is replaced with a fused silica capillary $(0.18 \mathrm{~mm}$ ID, length ca. $1 \mathrm{~m})$ to increase resistance for the inlet gas flow.

- A needle valve (SS-SS2-A, Swagelok Company, orifice size $0.81 \mathrm{~mm}$ ) is placed between the proportional control valve at the outlet of the cavity and the diaphragm pump, which makes it possible to adjust the pump rate.

It is noteworthy that we also tried to dilute the sample gas with helium in the ratio 1:20, in order to operate the unmodified WS-CRDS at the high flow rates for which it was designed. To measure the total amount of sample gas within the air-helium mixture we used an oxygen sensor (FOSPOR$\mathrm{R}$ probe, Ocean Optics Inc.). This sensor was installed within the WS-CRDS as close to the sample cavity as possible to get approximately simultaneous measurements of the oxygen and $\mathrm{CH}_{4}$ mixing ratios of the air-helium mixture. However, this approach was unsuccessful because uncertainties in the oxygen measurement were too large and measurements of $\mathrm{CH}_{4}$ mixing ratio could not be corrected for the dilution with helium without introducing unacceptably large errors.

\subsubsection{Cavity pressure and fitting routine}

The continuous flow of gas through the WS-CRDS is subject to dispersion (sample mixing). Thus, every signal in the continuous sample flow is smoothed when analyzed by the spectrometer.

The average time a sample molecule spends in each volume of the WS-CRDS is long when the spectrometer is operated at the low sample gas flow of $1.6 \mathrm{ml} \mathrm{min}^{-1}$, compared to default operation at gas flows between 70 and $400 \mathrm{ml} \mathrm{min}^{-1}$. Therefore, dispersion and memory effects in the WS-CRDS increase and reduce the optimal resolution of $\mathrm{CH}_{4}$ mixing ratio measurements.
To improve resolution, the pressure in the sample cavity, which is with ca. $33 \mathrm{~cm}^{3}$ by far the largest volume in the spectrometer, is reduced from $225 \mathrm{mbar}$ to $60 \mathrm{mbar}^{1}$. The internal volume of the WS-CRDS is reduced by switching to small-diameter tubing throughout the spectrometer. Furthermore, we removed a high-purity gas filter at the inlet of the spectrometer (Wafergard II F Micro In-Line Gas Filter, Entegris Inc.). The cavity remains protected from contamination by a second, identical filter upstream of the cavity. As a replacement for the first filter, we installed a small-volume, 0.5 micron filter at the inlet of the cavity (Valco filters for GC, ZBUFR1, VICI AG). Up to this date no degradation of the quality of $\mathrm{CH}_{4}$ mixing ratio measurements could be detected.

As a consequence of the lower cavity pressure and the volume reduction, sample gas dispersion and memory effects in the spectrometer decrease. We quantify this improvement in Sect. 3.2.3, where we compare the optimal resolution of modified and original WS-CRDS.

To determine the $\mathrm{CH}_{4}$ mixing ratio in air, the software of the WS-CRDS applies a spectral fit to the $\mathrm{CH}_{4}$ absorption feature. The low pressure in the sample cavity reduces pressure-broadening effects and, thus, sharpens the absorption line of $\mathrm{CH}_{4}$ (for detail see e.g. Di Rocco, 2004; Demtröder, 2003). A spectral fit tailored to the lower cavity pressure was provided and implemented into the software by the manufacturer Picarro. However, it turned out after the field campaign that the pressure reading of the WS-CRDS had a bias of several mbar. This caused instabilities in the custom-made spectral fit and, as a consequence, outliers in the $\mathrm{CH}_{4}$ mixing ratio measurements as shown in Fig. 3a (green line). The reason being that this fit (Levenberg-Marquardt algorithm) is bi-stable under the lowpressure conditions with two optimal points that correspond to two different mixing ratios. Hence, the fit switches between these two states depending on small differences between each spectrum. The red line in Fig. 3a shows measurements without outliers: during these measurements the instrument was running in its original mode with a cavity pressure of $225 \mathrm{mbar}$ and the corresponding spectral fit.

The above-mentioned modifications enable us to use a commercial instrument for measurements of $\mathrm{CH}_{4}$ mixing ratios from small air samples extracted from ice cores with a high temporal resolution. In principle, these modifications can improve the measurement resolution of any spectrometer. However, in the case of continuous flow, small-sample applications as described in this work, the internal volume of the sample cavity is critical and should be chosen to be as small as possible. Lowering the sample pressure in the cavity

\footnotetext{
${ }^{1}$ The reduced cavity pressure of 60 mbar was a recommendation of the manufacturer. Since then a reduced cavity pressure of 30 mbar was tested successfully. It is noteworthy that the standard deviation of $\mathrm{CH}_{4}$ mixing ratio measurements becomes worse with lower cavity pressure.
} 

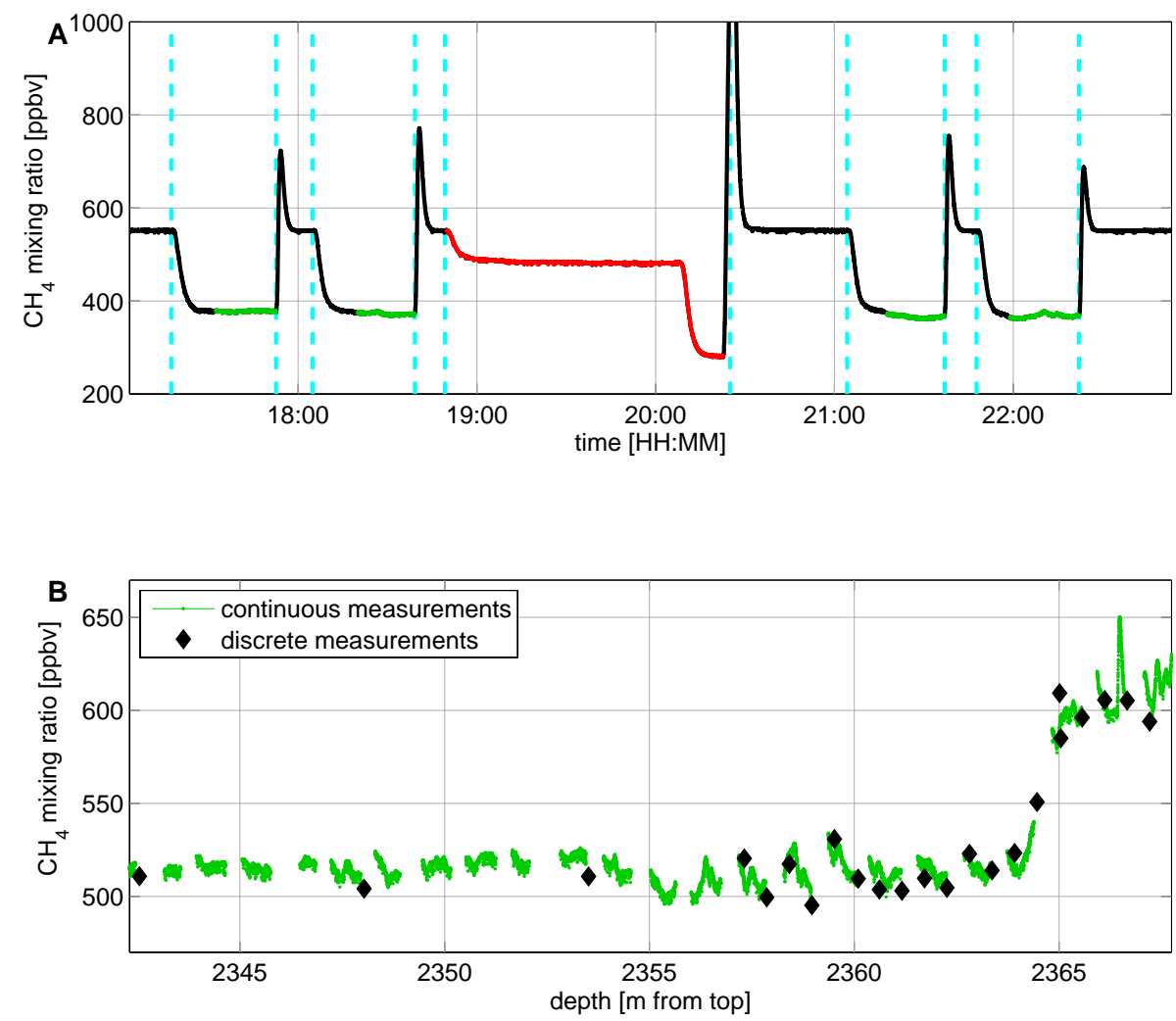

Fig. 4. (A) Approximately six hours of uncalibrated $\mathrm{CH}_{4}$ mixing ratios as measured by the WS-CRDS, containing four ice core measurements $\left(\mathrm{CH}_{4}\right.$ mixing ratio ca. $390 \mathrm{ppbv}$,) and a calibration (red line). Between two consecutive measurements, the WS-CRDS measures a mixture of deionized water and bottled gas (ca. $550 \mathrm{ppbv}$ ). Switches between this mixture and the sample are indicated by dashed cyan lines. Approximately the first third of each $1.1 \mathrm{~m}$ long run is discarded due to sample dispersion and memory effects leaving approximately $0.7 \mathrm{~m}$ of measurements (green). (B) Discrete measurements of $\mathrm{CH}_{4}$ mixing ratio along the NEEM deep ice core covering a depth between 2343-2368 m (black diamonds). 25 consecutive continuous measurements of $\mathrm{CH}_{4}$ mixing ratios along the NEEM deep ice core covering the same depth, each along $1.1 \mathrm{~m}$ of ice (green line). The continuous measurements have been corrected for the $+25 \mathrm{ppbv}$ bias compared to discrete measurements.

improves the measurements resolution, but decreases the precision due to a smaller signal-to-noise ratio. Hence, one has to find a compromise between resolution and precision for each application.

\section{Results}

\subsection{Field measurements}

Figure 4a shows ca. six hours of $\mathrm{CH}_{4}$ mixing ratio raw data as recorded by the WS-CRDS during the 2011 NEEM field season representing four CFA runs. Uncalibrated $\mathrm{CH}_{4}$ mixing ratios of the four CFA runs are around $390 \mathrm{ppbv}$, each along $1.1 \mathrm{~m}$ of ice. Between two consecutive measurements, the WS-CRDS measures a mixture of deionized water and bottled gas $\left(\mathrm{CH}_{4}\right.$ mixing ratio of ca. $\left.550 \mathrm{ppbv}\right)$. Valve switches (\#6 in Fig. 1) between this mixture and the sample are indicated by dashed cyan lines. The end of each measurement is clearly defined since ambient air briefly enters the system which results in spikes in the $\mathrm{CH}_{4}$ mixing ratio. Approximately the first third of each measurement run is discarded due to sample dispersion and memory effects. This leaves ca. $0.7 \mathrm{~m}$ per CFA run for non-contaminated $\mathrm{CH}_{4}$ mixing ratio measurements (green segments).

Figure $4 \mathrm{a}$ also shows measurements of two gas mixtures with known $\mathrm{CH}_{4}$ mixing ratios in red, which are injected into the system in order to calibrate the measurements (see Sect. 2.2) and to evaluate the response of the experimental setup to a stepwise change in $\mathrm{CH}_{4}$ mixing ratio (see Sect. 3.2.1).

In Fig. 4b we show 25 consecutive measurements of $\mathrm{CH}_{4}$ mixing ratios (green) on a depth scale measured over a period of ca. $24 \mathrm{~h}$ (ca. 2340-2370 $\mathrm{m}$ from top, NEEM deep ice core). We convert the time series of the measurements to a depth scale via the CFA melt rate of $3.2 \mathrm{~cm} \mathrm{~min}^{-1}$. The measurements cover a change in $\mathrm{CH}_{4}$ mixing ratio values from ca. $650 \mathrm{ppbv}$ to ca. $540 \mathrm{ppbv}$. The measurements are calibrated using the 2-point calibration described in Sect. 2.2. In a second step we correct the measurements for a $+25 \mathrm{ppbv}$ 
bias we found compared to discrete measurements of $\mathrm{CH}_{4}$ mixing ratios. As a comparison we show the discrete measurements of $\mathrm{CH}_{4}$ mixing ratio (black diamonds) which were conducted at the University of Bern (reproducibility \pm 10 ppbv, melt-refreeze extraction, gas chromatography).

The bias in our calibrated measurements suggests that the calibration of our experimental setup does not take into account all possible sources of error. A possible cause of the bias could be, that we inject the segmented flow for calibration downstream of the melt head. Thus, we do not include the melt head and the phase change from ice to water into our calibration. By doing so, we make the assumption that both the sample and the calibration mixture are in equilibrium (with a constant mixing ratio of dissolved $\mathrm{CH}_{4}$ molecules in the water phase) before the air-water mixture enters the debubbler. This, however, might not be the case and could lead to wrong correction factors for the calibration.

Furthermore, the water-to-gas ratio of the segmented flow for calibration differs slightly from the water-to-gas ratio of the sample flow which alters the mixing ratio of dissolved $\mathrm{CH}_{4}$ molecules. The lack of a precise gas flow meter in the experimental setup, makes it impossible to compare the gas flow rate of the segmented calibration flow with the sample flow. It is therefore possible that differences in the water-togas ratio result in wrong correction factors.

Also, the 21 reservoir of deionized water used for the segmented calibration flow (upper left in Fig. 1) is constantly purged with $20 \mathrm{ml} \mathrm{min}^{-1}$ of nitrogen gas (ca. $100 \%$ nitrogen). Thus, we can assume saturation of the deionized water with nitrogen. Once the nitrogen-saturated water is mixed with the calibration gas (ca. $70 \%$ nitrogen), the nitrogen mixing ratios of the gas and of the water will start to equilibrate. The extra nitrogen will raise the nitrogen content of the calibration gas and, thus, lower its $\mathrm{CH}_{4}$ mixing ratio. In this case, the correction factor of the calibration will be too high, which explains the positive bias in our results compared to discrete measurements of $\mathrm{CH}_{4}$ mixing ratio.

Finally, the calibration gases used during the field campaign (see Fig. 2a) are synthetic air standards, which do not contain Argon. Argon broadens the absorption spectra of $\mathrm{CH}_{4}$ and a lack of Argon in the calibration gas introduces a measurements bias. According to the manufacturer, the magnitude of this effect is less than $1 \mathrm{ppbv}$ at $\mathrm{CH}_{4}$ mixing ratios of $600 \mathrm{ppbv}$ and, thus, can only account for a small part of the bias found in our measurements.

As shown in Fig. 4b, we can correct our continuous measurements with discrete measurements at similar depth to account for the bias. When correcting the continuous measurements with discrete measurements, the uncertainty from the discrete measurements will propagate and worsen the earlier stated accuracy of $\pm 8 \mathrm{ppbv}$ for the continuous measurements.

Gaps within the continuous measurements in Fig. 4b are due to dispersion and mixing effects during the first third of each measurement which have to be discarded. The reason being that it takes approximately 10 min (one third of a CFA run) to replace most of the gas molecules in the sample cavity of the WS-CRDS and other parts of the experimental setup. These gaps could be minimized by reducing the large volumes in the experimental setup, like the gas extraction module and sample cavity of the WS-CRDS. Alternatively a larger CFA ice core sample would provide a higher gas flow and accelerate the exchange of gas molecules within the system.

\subsection{Resolution of continuous methane mixing ratio measurements}

\subsubsection{Measurement resolution}

To quantify dispersion and memory effects in the experimental setup and to estimate the resolution of $\mathrm{CH}_{4}$ mixing ratio measurements we investigate the response of the experimental setup to a stepwise change in $\mathrm{CH}_{4}$ mixing ratio. Here, we follow an approach similar to Gkinis et al. (2010), who used similar techniques to characterize a system for continuous measurements of stable isotopes of water using a WS-CRDS.

The continuous flow of gas through the experimental setup is subject to dispersion and memory effects. Thus, every signal in the continuous sample flow is smoothed when analyzed by the system. This sets a limit to the measuring resolution of the system. A stepwise change between two different $\mathrm{CH}_{4}$ mixing ratios is injected into the system via a 4-port valve (\#4 in Fig. 1). In the theoretical case of zero dispersion and memory effects, the change between two $\mathrm{CH}_{4}$ mixing ratios can be described by a scaled version of the Heaviside unit step function $\mathcal{H}(t)$ as:

$S(t)=\left(C_{2}-C_{1}\right) \mathcal{H}(t)+C_{1}$

where the valve switch takes place at $t=0$ and $C_{1}$ and $C_{2}$ are the $\mathrm{CH}_{4}$ mixing ratios of the two gas mixtures as measured by the WS-CRDS. The measured signal, which is smoothed by dispersion and memory effects, can be described as the convolution of $S(t)$ with a smoothing function $G$ :

$m(t)=[S * G](t)$,

where $m(t)$ is the signal as measured by the WS-CRDS. Figure 5a shows the normalized WS-CRDS signal as a response to a stepwise change in $\mathrm{CH}_{4}$ mixing ratios at a gas flow rate of $1.6 \mathrm{ml} \mathrm{min}^{-1}$ (black dots). A fit to the data using a scaled version of the cumulative distribution function (cdf) of a lognormal distribution is shown as a dashed red line. The derivative of the measured signal $\mathrm{d} m / \mathrm{d} t$ gives the response of the experimental setup to a scaled version of the $\delta_{\text {Dirac }}$ pulse:

$\frac{\mathrm{d} m}{\mathrm{~d} t}=\frac{\mathrm{d} S}{\mathrm{~d} t} * G=\left(C_{2}-C_{1}\right) \frac{\mathrm{d} \mathcal{H}}{\mathrm{d} t} * G=\left(C_{2}-C_{1}\right) \delta_{\text {Dirac }} * G$.

Figure $5 \mathrm{~b}$ shows the derivative of the normalized step response shown in Fig. 5a, i.e. the response of the system to a 
A

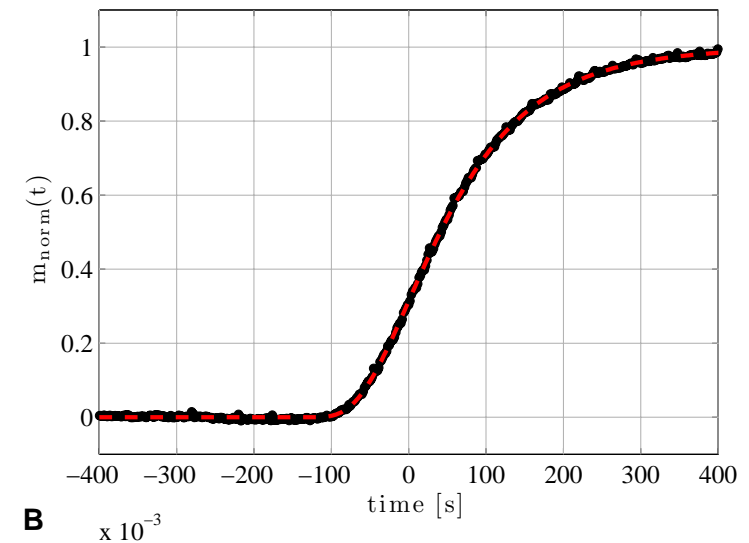

B

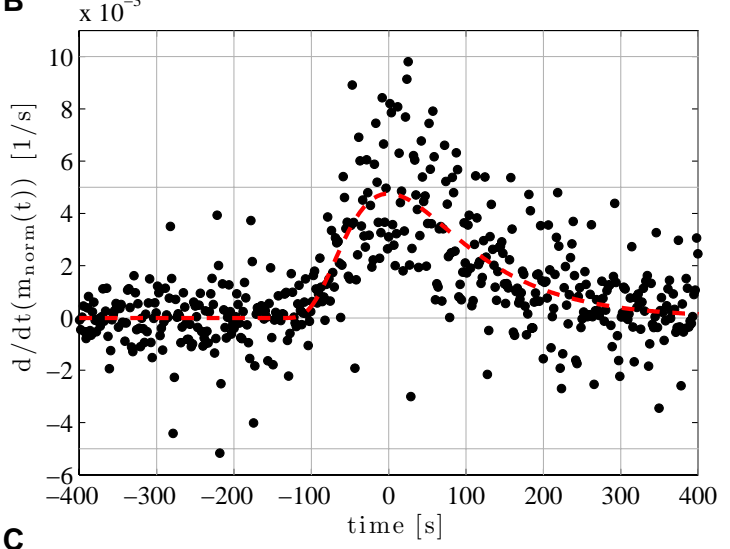

C

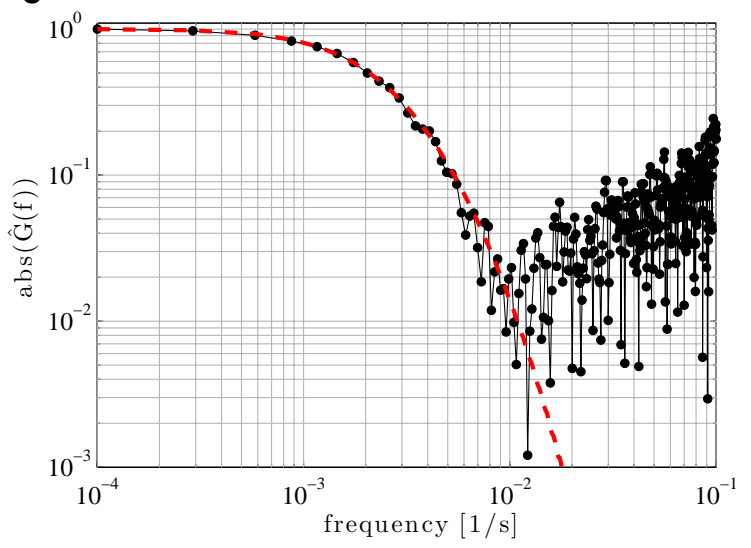

Fig. 5. (A) Normalized response of the complete experimental setup (except melt head) to a stepwise change in $\mathrm{CH}_{4}$ mixing ratio (black dots) and a cdf fit (dashed red line) as a function of measurement time. (B) The derivative of the normalized step response (black dots) and of the cdf fit (dashed red line) with respect to the measurement time. (C) The transfer functions of the experimental setup (black dots) and of the theoretical case of zero-noise measurements (dashed red line).

$\delta_{\text {Dirac }}$ pulse (black dots). The derivative of the cdf fit is shown as a dashed red line. We define the normalized derivative $m^{\prime}$ as

$m^{\prime}=\frac{\mathrm{d} m}{\mathrm{~d} t} *\left(C_{2}-C_{1}\right)^{-1}$.
The transfer function $\hat{G}(f)$ of the experimental setup is the Fourier transform of the normalized derivative $m^{\prime}$. The magnitude of the transfer function describes how the amplitude of a periodic input signal of a certain frequency is damped when analyzed by the system. Figure 5c shows the magnitude of the transfer function (black dots) of the system. For example, the amplitude of a periodic input signal with a frequency of $0.004 \mathrm{~s}^{-1}$ is attenuated by $80 \%$ after being analyzed by the system compared to the amplitude of the input signal. The transfer functions of the derivative of the cdf fit represents the theoretical zero-noise case (dashed red line). Due to noise in the measurements, it is not possible to resolve any periodic input signal with a frequency larger than ca. $0.01 \mathrm{~s}^{-1}$ which sets the optimal temporal resolution of our system.

We convert the time scale $t$ in seconds to a length scale $x$ in meters by using the CFA melt rate of ca. $3.2 \mathrm{~cm} \mathrm{~min}^{-1}$. Hereby we can estimate the spatial resolution of $\mathrm{CH}_{4}$ mixing ratio measurements along an ice core. This determines the maximal spatial resolution of our measurement technique (WS-CRDS and front-end) to be ca. $5 \mathrm{~cm}$ of ice, corresponding to ca. $100 \mathrm{~s}$ of measurement time. Thus, our system can detected a damped version of periodic input signals with a wavelength longer than $5 \mathrm{~cm}$.

The spatial resolution of $5 \mathrm{~cm}$ in combination with the high measurements speed of typically $20-25 \mathrm{~m}$ of ice per day is the main advantage of our measurement technique. The semiautomated method with a gas chromatograph coupled to the CFA system offers the same measurement speed but the resolution is limited to $15 \mathrm{~cm}$ (Schüpbach et al., 2009). Discrete measurements of $\mathrm{CH}_{4}$ mixing ratios from ice cores yield a typical measurement speed of 10-12 samples per day and a resolution of $140 \mathrm{~cm}$ (Loulergue et al., 2008) up to $100 \mathrm{~cm}$ for detailed studies over short parts of the core (e.g. Flückiger et al., 2004; Huber et al., 2006).

\subsubsection{Comparing the measurement resolution to the firn response}

In this section we compare the estimated resolution of the analytical setup to the resolution available from different ice cores using firn modeling.

The porous firn layer at the top $40-120 \mathrm{~m}$ of the ice sheet causes diffusive smoothing of the atmospheric signal (e.g. Schwander et al., 1988; Battle et al., 1996). This limits the temporal resolution at which variations in atmospheric composition are preserved in the air bubbles. The firn acts as a low-pass filter for the atmospheric signal, and high frequency variations, such as the annual cycles of various trace gases, are not recorded in the ice. Here we shall study the frequency response of the firn layer to assess how atmospheric variations at different frequencies are attenuated and preserved. Knowing the accumulation rate and thinning function in the ice sheet, the temporal $\mathrm{CH}_{4}$ variations in the atmosphere can be mapped onto spatial $\mathrm{CH}_{4}$ variations along a drilled ice 
core. By comparing the transfer function of the firn to that of our experimental setup we can assess whether our measurements capture all the $\mathrm{CH}_{4}$ variations recorded in the ice core, i.e. whether we are over- or undersampling the available climatic signal.

We use the Center for Ice and Climate firn air model (Buizert et al., 2011) to model gas transport in the porous firn. The model was adapted to allow calculation of mixing ratios in the closed pores, using the porosity parameterization of Goujon et al. (2003). We force the model at the surface with a unit step function in $\mathrm{CH}_{4}$ mixing ratio, equivalent to the step function we used to characterize the experimental setup. We model the firn response on a time scale; this can easily be converted to a depth scale by multiplying with the annual layer thickness $\lambda$ at the depth considered. Ice flow reduces the layer thicknesses towards the bed; we base our estimates of $\lambda$ on a preliminary NEEM depth-age scale constructed by matching of reference horizons to the NGRIP GICC05 time scale (S. O. Rasmussen, personal communication, 2011).

We analyze four time slices representing different climatic conditions, and degrees of annual layer thinning. The first two represent the early and late Holocene, with ages of $1 \mathrm{kyr}$ and $7 \mathrm{kyr}$ before present $(1 \mathrm{kyr}=1000 \mathrm{yr})$; these periods are present in the NEEM ice core at annual layer thicknesses of $\lambda=18$ and $\lambda=11 \mathrm{~cm}$, respectively. For both we use the modern day firn air transport characteristics as described by Buizert et al. (2011). The effects of Holocene temperature and accumulation variability on the firn transport properties are not taken into account as they are small (Schwander et al., 1997; Goujon et al., 2003). Note that for these two cases the time response of the firn is assumed to be identical; they only differ in the amount of layer thinning they experienced. Atmospheric variation in the late Holocene will be more easily resolved, due to less severe layer thinning in this part of the core compared to the early Holocene.

The other two time slices represent the glacial period, with ages of $23 \mathrm{kyr}$ (LGM) and $66 \mathrm{kyr}$ before present; with $\lambda=1$ and $\lambda=0.5 \mathrm{~cm}$, respectively. Modeling the firn transport in the past requires detailed knowledge of the firn denisty profile and transport properties. Unfortunately the relationship between density and diffusivity is highly site specific and not well represented by measurements on finite firn samples (Fabre et al., 2000). The current day diffusivity-depth relationship can be reconstructed using measurements of trace gas mixing ratios in firn air samples (Rommelaere et al., 1997; Trudinger et al., 1997). However, since climatic conditions strongly influence the firn transport properties, this is of limited use when considering e.g. ice from glacial periods (Schwander et al., 1997). We estimate the LGM accumulation at NEEM to be around $8 \mathrm{~cm} \mathrm{yr}^{-1}$ ice equivalent based on reconstructions for the NGRIP ice core (Andersen et al., 2004); our estimate of the mean annual temperature is $-50^{\circ} \mathrm{C}$ based on an inversion study of borehole thermometry at GRIP by Dahl-Jensen et al. (1998). With an accumulation rate of $8 \mathrm{~cm} \mathrm{yr}^{-1}$ and a mean annual temperature of $-49.5^{\circ} \mathrm{C}$
(Battle et al., 1996), South Pole offers a good modern day analog for NEEM during the LGM. Consequently we have tuned the effective diffusivity of the model to firn air measurements from modern day South Pole. We increased the depth of convective mixing until gravitational fractionation matched LGM data from the GRIP core (Schwander et al., 1997).

In Fig. 6a we show the comparison of the firn responses from the four analyzed time slices. Furthermore, we compare the firn responses to the normalized step-response of the experimental setup (see Sect. 3.2.1). For the normalized step-response we converted from measurement time to depth using the CFA melt rate of ca. $3.2 \mathrm{~cm} \mathrm{~min}^{-1}$. Figure $6 \mathrm{~b}$ shows the transfer functions of the five responses shown in Fig. 6a as a function of frequency $f$ and wavenumber $k$.

It must be noted that the modeled firn response, particularly during the glacial, has a high uncertainty. By using South Pole as a realistic modern analog this uncertainty is minimized; we estimate the firn response time shoud be accurate within $50 \%$ for the glacial, and within $25 \%$ for the Holocene. Even with such a high uncertainty we can conclude that the continuous measurements of $\mathrm{CH}_{4}$ mixing ratio can resolve all climatically relevant $\mathrm{CH}_{4}$ variations in the firn column with wavenumbers (frequencies) smaller than $0.2 \mathrm{~cm}^{-1}\left(0.01 \mathrm{~s}^{-1}\right)$ down to a depth of $1980 \mathrm{~m}(66 \mathrm{kyr} \mathrm{BP})$. $\mathrm{CH}_{4}$ variations in the firn column with wavenumbers larger than $0.2 \mathrm{~cm}^{-1}$ cannot be resolved due to measurement noise.

Nevertheless, a higher resolution of the continuous measurements of $\mathrm{CH}_{4}$ mixing ratios from ice cores would be beneficial. A higher measurement resolution would shorten the gaps between consecutive measurements (see Sect. 3.1). Furthermore, non-atmospheric variations in $\mathrm{CH}_{4}$ mixing ratio found in the ice could be resolved better, such as in-situ production of $\mathrm{CH}_{4}$ or high $\mathrm{CH}_{4}$ mixing ratios associated with melt layers.

\subsubsection{Improving measurement resolution of the WS-CRDS}

To quantify the improvement in resolution due to the WSCRDS modification we use the same techniques as described in Sect. 3.2.1. Omitting the front-end, gas was directly injected into the original and modified spectrometer, respectively. Figure 7a shows the normalized responses of the original analyzer (green squares) and the modified analyzer (black dots) to an identical stepwise change in $\mathrm{CH}_{4}$ mixing ratio at a gas flow rate of $2 \mathrm{ml} \mathrm{min}^{-1}$. A cdf fit to the data is shown as a dashed red line. The modified analyzer responds faster to a change in $\mathrm{CH}_{4}$ mixing ratio: it takes $250 \mathrm{~s}$ to go from $10 \%$ to $90 \%$ of the normalized step using the original analyzer, whereas it takes only $48 \mathrm{~s}$ using the modified analyzer.

Figure $7 \mathrm{~b}$ shows the time derivative of the normalized responses from which we calculate the transfer functions of the original and modified analyzer as shown in Fig. 7c. The amplitude of a periodic input signal with a frequency of 

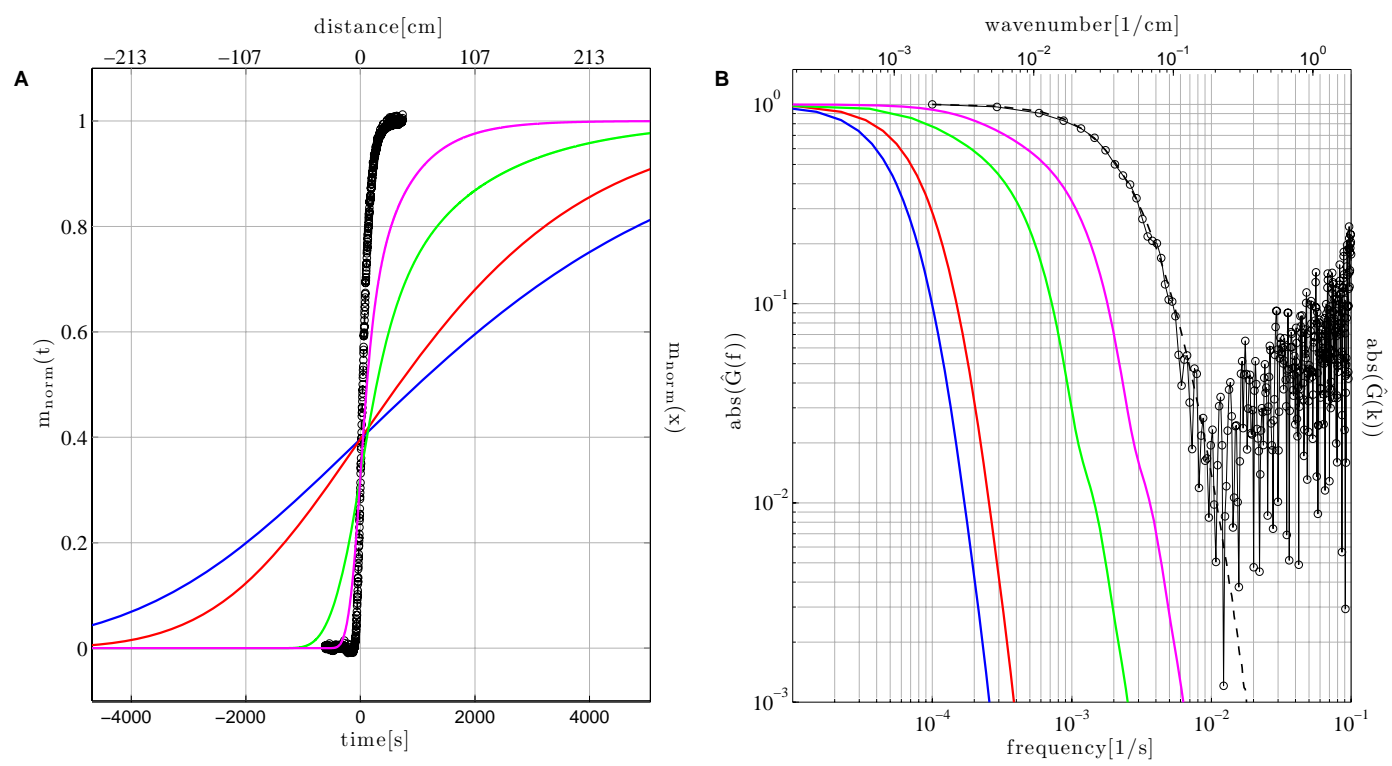

Fig. 6. (A) Firn responses from four different time slices compared to the response of the experimental setup to a stepwise change in $\mathrm{CH}_{4}$ mixing ratio. Curves are aligned with maximum slope at $t=0 \mathrm{~s}$. (B) The transfer functions of the responses shown in the left panel.

$0.001 \mathrm{~s}^{-1}$ e.g. is attenuated by $20 \%$ of the input amplitude in the original analyzer. However, in the modified analyzer the same input signal is not attenuated noticeably. By comparing the transfer functions of the analyzer to the transfer function of the cdf fit (dashed red lines) we find that the original analyzer cannot resolve periodic input signals with frequencies larger than ca. $0.01 \mathrm{~s}^{-1}$ due to noise in the measurements. Using the modified analyzer it is possible to resolve periodic input signals with frequencies up to ca. $0.03 \mathrm{~s}^{-1}$. We can conclude that the modifications on the WS-CRDS improved the resolution of $\mathrm{CH}_{4}$ mixing ratio measurement, which makes continuous measurements of $\mathrm{CH}_{4}$ mixing ratios from ice cores feasible.

Comparing the optimal resolution of the modified spectrometer $\left(0.03 \mathrm{~s}^{-1}\right)$ with the optimal resolution of the modified spectrometer plus front-end as derived in Sect. 3.2.1 $\left(0.01 \mathrm{~s}^{-1}\right)$, we conclude that the front-end has a significant effect on the optimal resolution of continuous measurements of $\mathrm{CH}_{4}$ mixing ratios from ice cores. To improve resolution even further it is necessary to minimize sample volumes both in the spectrometer (e.g. sample cavity) and in the front end (e.g. gas extraction module).

For frequencies larger than ca. $0.01 \mathrm{~s}^{-1}$ the transfer function of the original analyzer shows flat (white) noise, which is independent of frequency (green squares in Fig. 7c). However, the transfer function of the modified analyzer plus frontend shows frequency-dependent noise (Figs. 5c and 6b). For frequencies $f$ larger than ca. $0.01 \mathrm{~s}^{-1}$ the transfer function scales approximately with $f$. We cannot determine whether the cause of this noise behavior lies in the modified analyzer or the front-end.

\section{Summary and conclusions}

We modified a commercially available WS-CRDS to make it suitable for continuous $\mathrm{CH}_{4}$ mixing ratio measurements from ice cores in combination with a CFA system. The modified flow path enables stable operation of the WS-CRDS at a gas flow of ca. $1.6 \mathrm{ml} \mathrm{min}^{-1}$. The reduced cavity pressure improves the resolution of the measurements considerably, allowing for highly resolved continuous measurements of $\mathrm{CH}_{4}$ mixing ratios. The measurement resolution (ca. $5 \mathrm{~cm}$ of ice) of the complete experimental setup, i.e. CFA system (except melt head), gas extraction module and WS-CRDS combined, is sufficient to resolve all climatic relevant $\mathrm{CH}_{4}$ variations in the firn at least down to a depth of $1980 \mathrm{~m}$ of the NEEM deep ice core.

For the current system we determine a precision of $0.8 \mathrm{ppbv}(1 \sigma)$. We find that the limiting factor of the stability of the measurement technique is the gas extraction system and not the WS-CRDS. Given the current stability of the system one calibration per day is not sufficient to capture and correct for all drifts in the measurement. By improving the stability of the gas extraction the precision of $\mathrm{CH}_{4}$ mixing ratio measurements could be improved further.

We estimate the accuracy of continuous $\mathrm{CH}_{4}$ mixing ratio measurements to be \pm 8 ppbv. By comparing the continuous measurements of $\mathrm{CH}_{4}$ mixing ratios with traditional discrete measurements from the same ice core we find a concentration-independent bias of ca. $25 \mathrm{ppbv}$ between the two techniques. We need to correct for this bias using discrete measurements at similar depth.

To improve the quality of future measurements, the field calibration procedure needs to be refined. A review of the 
A
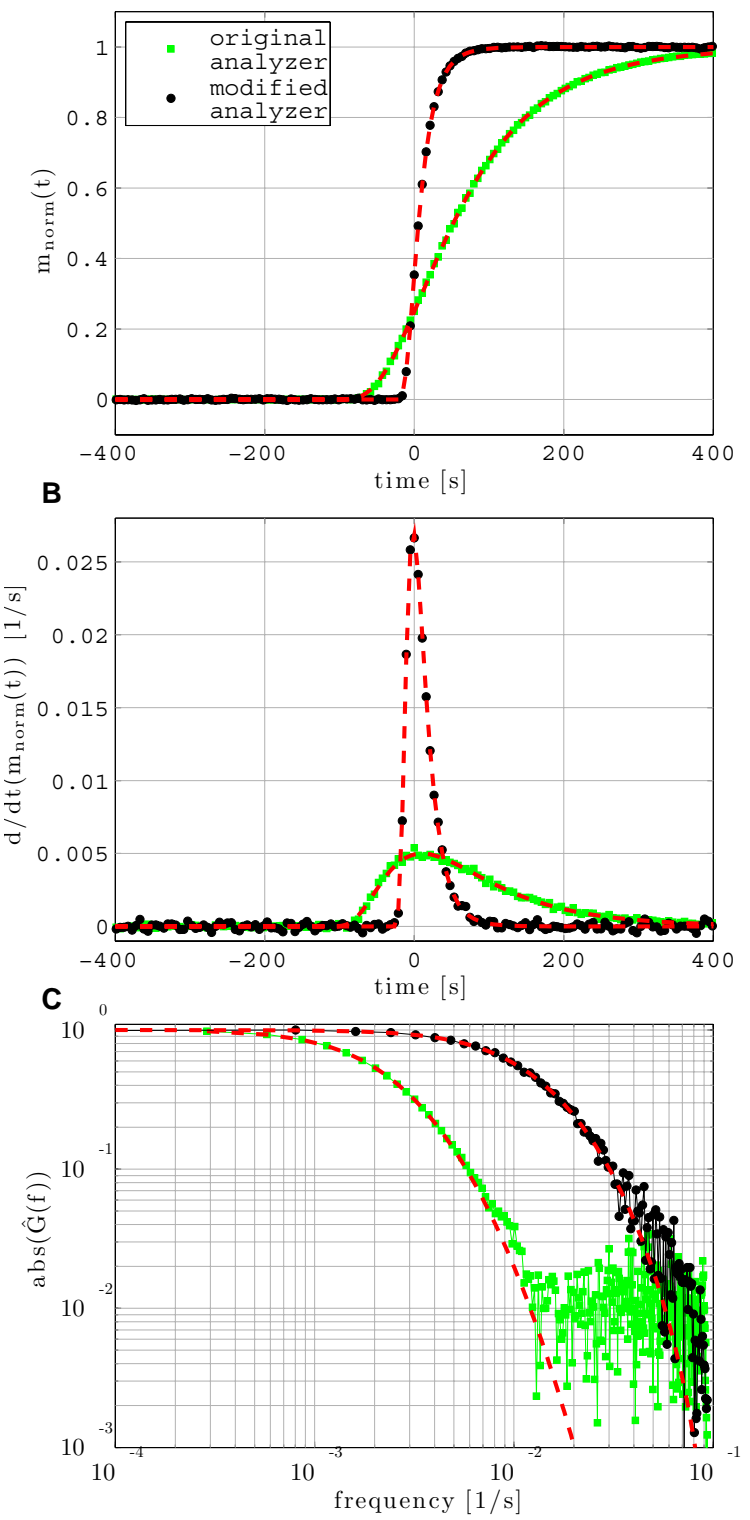

Fig. 7. (A) Normalized response of the original (green squares) and the modified analyzer (black dots) to a stepwise change in $\mathrm{CH}_{4}$ mixing ratio plotted against measurement time in seconds. Cdf fits to the measurements are shown as dashed red lines. (B) The time derivative of the normalized responses from (A). (C) The transfer functions of the original and modified analyzer. The dashed lines show the transfer functions of the analyzer in the theoretical case of zero-noise measurements.

importance of calibration procedures can be found in Werle et al. (2004). Our calibration procedure needs to be completed by measurements of "zero air" (ambient air devoid of the target substance $\mathrm{CH}_{4}$ ) and checks of linearity by measuring calibration gases of three known $\mathrm{CH}_{4}$ mixing ratios (closely covering the dynamic range as found in the ice cores analyzed). Hereby, potential drifts in the measurements of the spectrometer can be detected (and corrected for) and the accuracy of $\mathrm{CH}_{4}$ mixing ratio measurements is optimized. Additionally, the optimal interval between individual calibrations needs to be determined by further Allan variance tests to improve measurement stability.

We conclude that our new technique for continuous measurements of $\mathrm{CH}_{4}$ mixing ratios from ice cores provides measurements of high resolution and precision. The spatial resolution of $5 \mathrm{~cm}$ in combination with the high measurement speed of typically $20-25 \mathrm{~m}$ of ice per day is the main advantage of our measurement technique. The new technique is coupled to a CFA system where the chemical composition of the ice core is measured. Therefore, our system does not require ice core samples solely dedicated for measurements of $\mathrm{CH}_{4}$ mixing ratio.

Acknowledgements. We like to thank Eric Crosson, Chris Rella and Aaron van Pelt from Picarro Inc. for their support of this work. The authors did not receive any financial support from Picarro for the work presented in this study. NEEM is directed and organised by the Center for Ice and Climate at the Niels Bohr Institute and US NSF, Oce of Polar Programs. It is supported by funding agencies and institutions in Belgium (FNRS-CFB and FWO), Canada (GSC), China (CAS), Denmark (FIST), France (IPEV, CNRS/INSU, CEA and ANR), Germany (AWI), Iceland (RannIs), Japan (NIPR), Korea (KOPRI), The Netherlands (NWO/ALW), Sweden (VR), Switzerland (SNF), UK (NERC) and the USA (US NSF, Oce of Polar Programs). LGGE contribution was supported by the French ANR NEEM (ANR-07-VULN-09-001). This is Past4Future contribution no. 14. The research leading to these results has received funding from the European Union's Seventh Framework programme (FP7/2007-2013) under grant agreement no. 243908, "Past4Future. Climate change - Learning from the past climate".

Edited by: P. Werle

\section{References}

Allan, D.: Statistics of atomic frequency standards, Proc. IEEE, 54, 221-230, 1966.

Andersen, K., Azuma, N., Barnola, J., Bigler, M., Biscaye, P., Caillon, N., Chappellaz, J., Clausen, H., Dahl-Jensen, D., Fischer, H., Flückiger, J., Fritzsche, D., Fujii, Y., Goto-Azuma, K., Gronvold, K., Gundestrup, N., Hansson, M., Huber, C., Hvidberg, C., Johnsen, S., Jonsell, U., Jouzel, J., Kipfstuhl, S., Landais, A., Leuenberger, M., Lorrain, R., Masson-Delmotte, V., Miller, H., Motoyama, H., Narita, H., Popp, T., Rasmussen, S., Raynaud, D., Röthlisberger, R., Ruth, U., Samyn, D., Schwander, J., Shoji, H., Siggard-Andersen, M., Steffensen, J., Stocker, T., Sveinbjornsdottir, A., Svensson, A., Takata, M., Tison, J., Thorsteinsson, T., Watanabe, O., Wilhelms, F., and White, J.: High-resolution record of Northern Hemisphere climate extending into the last interglacial period, Nature, 431, 147-151, 2004. 
Battle, M., Bender, M., Sowers, T., Tans, P., Butler, J., Elkins, J., Ellis, J., Conway, T., Zhang, N., Lang, P., and Clarke, A.: Atmospheric gas concentrations over the past century measured in air from firn at the South Pole, Nature, 383, 231-235, doi:10.1038/383231a0, 1996.

Bigler, M., Svensson, A., Kettner, E., Vallelonga, P., Nielsen, M., and Steffensen, J.: Optimization of High-Resolution Continuous Flow Analysis for Transient Climate Signals in Ice Cores, Environ. Sci. Technol., 45, 4483-4489, doi:10.1021/es200118j, 2011.

Blunier, T. and Brook, E.: Timing of millennial-scale climate change in Antarctica and Greenland during the last glacial period, Science, 291, 109-112, doi:10.1126/science.291.5501.109, 2001.

Blunier, T., Spahni, R., Barnola, J.-M., Chappellaz, J., Loulergue, L., and Schwander, J.: Synchronization of ice core records via atmospheric gases, Clim. Past, 3, 325-330, doi:10.5194/cp-3-3252007, 2007.

Buizert, C., Martinerie, P., Petrenko, V. V., Severinghaus, J. P., Trudinger, C. M., Witrant, E., Rosen, J. L., Orsi, A. J., Rubino, M., Etheridge, D. M., Steele, L. P., Hogan, C., Laube, J. C., Sturges, W. T., Levchenko, V. A., Smith, A. M., Levin, I., Conway, T. J., Dlugokencky, E. J., Lang, P. M., Kawamura, K., Jenk, T. M., White, J. W. C., Sowers, T., Schwander, J., and Blunier, T.: Gas transport in firn: multiple-tracer characterisation and model intercomparison for NEEM, Northern Greenland, Atmos. Chem. Phys. Discuss., 11, 15975-16021, doi:10.5194/acpd-11-159752011, 2011.

Capron, E., Landais, A., Chappellaz, J., Schilt, A., Buiron, D., Dahl-Jensen, D., Johnsen, S. J., Jouzel, J., Lemieux-Dudon, B., Loulergue, L., Leuenberger, M., Masson-Delmotte, V., Meyer, H., Oerter, H., and Stenni, B.: Millennial and sub-millennial scale climatic variations recorded in polar ice cores over the last glacial period, Clim. Past, 6, 345-365, doi:10.5194/cp-6-3452010, 2010.

Chappellaz, J., Blunier, T., Raynaud, D., Barnola, J., Schwander, J., and Stauffer, B.: Synchronous changes in atmospheric $\mathrm{CH}_{4}$ and Greenland climate between 40 and 8 kyr BP, Nature, 366, 443445, doi:10.1038/366443a0, 1993.

Crosson, E.: A cavity ring-down analyzer for measuring atmospheric levels of methane, carbon dioxide, and water vapor, Appl. Phys. B-Lasers O., 92, 403-408, doi:10.1007/s00340-008-3135y, 2008.

Dällenbach, A., Blunier, T., Flückiger, J., Stauffer, B., Chappellaz, J., and Raynaud, D.: Changes in the atmospheric $\mathrm{CH}_{4}$ gradient between Greenland and Antarctica during the Last Glacial and the transition to the Holocene, Geophys. Res. Lett., 27, 10051008, doi:10.1029/1999GL010873, 2000.

Dahl-Jensen, D., Mosegaard, K., Gundestrup, N., Clow, G., Johnsen, S., Hansen, A., and Balling, N.: Past temperatures directly from the Greenland ice sheet, Science, 282, 268-271, doi:10.1126/science.282.5387.268, 1998.

Demtröder, W.: Laser Spectroscopy, Springer-Verlag, 2003.

Di Rocco, H.: The exact expression of the Voigt profile function, J. Quant. Spectrosc. Ra., 92, 231-237, doi:10.1016/j.jqsrt.2004.08.002, 2004.

Fabre, A., Barnola, J., Arnaud, L., and Chappellaz, J.: Determination of gas diffusivity in polar firn: comparison between experimental measurements and inverse modeling, Geophys. Res. Lett., 27, 557-560, doi:10.1029/1999GL010780, 2000.
Flückiger, J., Blunier, T., Stauffer, B., Chappellaz, J., Spahni, R., Kawamura, K., Schwander, J., Stocker, T., and Dahl-Jensen, D.: $\mathrm{N}_{2} \mathrm{O}$ and $\mathrm{CH}_{4}$ variations during the last glacial epoch: Insight into global processes, Global Biochem. Cy., 18, GB1020, doi:10.1029/2003gb002122, 2004.

Gkinis, V., Popp, T., Johnsen, S., and Blunier, T.: A continuous stream flash evaporator for the calibration of an IR cavity ring-down spectrometer for the isotopic analysis of water, Isot. Environ. Healt. S., 46, 463-475, doi:10.1080/10256016.2010.538052, 2010.

Goujon, C., Barnola, J., and Ritz, C.: Modeling the densification of polar firn including heat diffusion: Application to close-off characteristics and gas isotopic fractionation for Antarctica and Greenland sites, J. Geophys. Res., 108, 4792, doi:10.1029/2002JD003319, 2003.

Güllük, T., Wagner, H., and Slemr, F.: A high-frequency modulated tunable diode laser absorption spectrometer for measurements of $\mathrm{CO}_{2}, \mathrm{CH}_{4}, \mathrm{~N}_{2} \mathrm{O}$, and $\mathrm{CO}$ in air samples of a few cm, Rev. Sci. Instrum., 68, 230-239, 1997.

Güllük, T., Slemr, F., and Stauffer, B.: Simultaneous measurements of $\mathrm{CO}_{2}, \mathrm{CH}_{4}$, and $\mathrm{N}_{2} \mathrm{O}$ in air extracted by sublimation from Antarctica ice cores: confirmation of the data obtained using other extraction techniques, J. Geophys. Res., 103, 15971$15978,1998$.

Huber, C., Leuenberger, M., Spahni, R., Flückiger, J., Schwander, J., Stocker, T., and Johnsen, S.: Isotope calibrated Greenland temperature record over Marine Isotope Stage 3 and its relation to $\mathrm{CH}_{4}$, Earth Planet. Sc. Lett., 243, 504-519, doi:10.1016/j.eps1.2006.01.002, 2006.

Kaufmann, P., Federer, U., Hutterli, M., Bigler, M., Schüpbach, S., Ruth, U., Schmitt, J., and Stocker, T.: An improved continuous flow analysis system for high-resolution field measurements on ice cores, Environ. Sci. Technol., 42, 8044-8050, doi:10.1021/es8007722, 2008.

Loulergue, L., Schilt, A., Spahni, R., Masson-Delmotte, V., Blunier, T., Lemieux, B., Barnola, J., Raynaud, D., Stocker, T., and Chappellaz, J.: Orbital and millennial-scale features of atmospheric $\mathrm{CH}_{4}$ over the past 800,000 years, Nature, 453, 383-386, doi:10.1038/nature06950, 2008.

Mitchell, L., Brook, E., Sowers, T., McConnell, J., and Taylor, K.: Multidecadal variability of atmospheric methane, 1000-1800 CE, J. Geophys. Res.-Biogeo., 116, G02007, doi:10.1029/2010jg001441, 2011.

Press, W., Flannery, B., Teukolsky, S., and Vetterling, W.: Numerical recipes, vol. 3, Cambridge Univ. Press, 2007.

Rella, C.: Accurate Greenhouse Gas Measurements in Humid Gas Streams Using the Picarro G1301 Carbon Dioxide/Methane/Water Vapor Gas Analyzer, Tech. rep., Picarro Inc.,www.picarro.com/assets/docs/ White_Paper_G1301_Water_Vapor_Correction.pdf (last access: 8 May 2012), 2010.

Rommelaere, V., Arnaud, L., and Barnola, J.: Reconstructing recent atmospheric trace gas concentrations from polar firn and bubbly ice data by inverse methods, J. Geophys. Res., 102, 3006930083, doi:10.1029/97JD02653, 1997.

Schüpbach, S., Federer, U., Kaufmann, P., Hutterli, M., Buiron, D., Blunier, T., Fischer, H., and Stocker, T.: A new method for high-resolution methane measurements on polar ice cores using continuous flow analysis, Environ. Sci. Technol., 43, 5371, 
doi:10.1021/es9003137, 2009.

Schüpbach, S., Federer, U., Bigler, M., Fischer, H., and Stocker, T. F.: A refined TALDICE-1a age scale from 55 to $112 \mathrm{ka}$ before present for the Talos Dome ice core based on highresolution methane measurements, Clim. Past, 7, 1001-1009, doi:10.5194/cp-7-1001-2011, 2011.

Schwander, J., Stauffer, B., and Sigg, A.: Air mixing in firn and the age of the air at pore close-off, Ann. Glaciol., 10, 141-145, 1988.

Schwander, J., Sowers, T., Barnola, J., Blunier, T., Fuchs, A., and Malaizé, B.: Age scale of the air in the summit ice: Implication for glacial-interglacial temperature change, J. Geophys. Res., 102, 19483-19493, doi:10.1029/97JD01309, 1997.

Sowers, T., Brook, E., Etheridge, D., Blunier, T., Fuchs, A., Leuenberger, M., Chappellaz, J., Barnola, J., Wahlen, M., Deck, B., and Weyhenmeyer, C.: An interlaboratory comparison of techniques for extracting and analyzing trapped gases in ice cores, J. Geophys. Res.-Oceans, 102, 26527-26538, doi:10.1029/97JC00633, 1997.
Stowasser, C., Buizert, C., Gkinis, V., Chappellaz, J., Schüpbach, S., Bigler, M., Faïn, X., Sperlich, P., Baumgartner, M., Schilt, A., and Blunier, T.: Continuous measurements of methane mixing ratios from ice cores, Atmos. Meas. Tech. Discuss., 5, 211-244, doi:10.5194/amtd-5-211-2012, 2012.

Trudinger, C., Enting, L., Etheridge, D., Francey, R., Levchenko, V., Steele, L., Raynaud, D., and Arnaud, L.: Modeling air movement and bubble trapping in firn, J. Geophys. Res., 102, 6747-6763, doi:10.1029/96JD03382, 1997.

Werle, P.: Accuracy and precision of laser spectrometers for trace gas sensing in the presence of optical fringes and atmospheric turbulence, Appl. Phys. B, 10, 251-253, doi:10.1007/s00340010-4165-9, 2011.

Werle, P., Mazzinghi, P., D’Amato, F., Rosa, M. D., Maurer, K., and Slemr, F.: Signal processing and calibration procedures for in situ diode-laser absorption spectroscopy, Spectrochim. Acta A, 60, 1685-1705, doi:10.1016/j.saa.2003.10.013, 2004. 